\title{
Management of perianal abscess and fistula-in-ano in infants and children
}

\author{
Jinyoung Park, MD, PhD \\ Department of Pediatric Surgery, Kyungpook National University Hospital, School of Medicine, Kyungpook National University, Daegu, Korea
}

Perianal abscesses and fistula-in-ano are common diseases in infants and children that develop from infection in abnormally deep crypts of Morgagni. They are often encountered in infants younger than 12 months and display an extreme male predominance. ${ }^{1,2)}$ This sex-based difference may be explained by androgen excess or androgen-sensitive glands. ${ }^{11}$ The abscess typically presents as a fluctuant tender mass in the perianal region, most commonly in the 3 o'clock and 9 o'clock positions. As many as $20 \%-85 \%$ perianal abscesses are reported to progress to a fistula-in-ano. ${ }^{1)}$ Therefore, perianal abscess and fistulain-ano could be considered the same disease in continuity. The fistula-in-ano is commonly located lateral to the anus rather than at the midline. The management of perianal abscess and fistula-in-ano during childhood remains controversial because it depends on the pediatric surgeon's preference, especially regarding conservative or surgical treatment, use of antibiotics, and surgical timing. ${ }^{3-6)}$ Therefore, the optimal management of perianal abscesses and fistula-in-ano has not yet been established.

Lack of consensus in the treatment of these diseases makes choosing treatment difficult. Chang et al..$^{2)}$ advocated that conservative treatment for perianal abscess and fistula-in-ano could be the first choice of treatment. Christison-Lagay et al. . $^{7}$ reported the risk of fistula formation with nonoperative treatment of perianal abscess in infants. Of 83 patients who underwent surgical drainage, 50 (60.2\%) developed a fistula, whereas among 57 patients who did not undergo drainage, only $9(15.8 \%)$ developed a fistula. They concluded that local hygiene and systemic antibiotics without surgical drainage minimized fistula formation. Boenicke et al. ${ }^{8)}$ described the efficiency of conservative treatment of perianal abscesses in children and predictors of therapy failure. However, there is some confusion regarding the definition of conservative treatment for perianal abscess. In this article, the authors defined incision and drainage of the perianal abscess as surgical treatment and local care including hygiene, sitz bath, and antibiotics as conservative treatment. ${ }^{8)}$ However, other articles defined incision and drainage with local care of the perianal abscess as conservative treatment. ${ }^{2)}$

There are different opinions regarding use of antibiotics in the treatment of perianal abscess and fistula-in-ano in literature. Afşarlar et al. ${ }^{1)}$ concluded that simple drainage of the perianal abscess with additional antibiotic therapy reduces the development of fistula-in-ano. However, the use of antibiotics had no influence on perianal abscess recurrence. Some authors reported that antibiotic use was ineffective. ${ }^{4,6,9)}$ Chang et al. ${ }^{2)}$ did not routinely use oral antibiotics except in cases of severe inflammation or systemic manifestation such as fever and irritability. They described that oral antibiotics did not change the lesion or worsened it by diarrhea. They also reported that feeding formula, changing from breast feeding to bottle feeding, or providing mixed feeding improved stooling but did not affect the duration of conservative treatment.

Although sitz baths are prescribed if the abscess does not appear to be fluctuant, incision and drainage with or without general or topical anesthesia is the most commonly accepted treatment of perianal abscess. The treatment of a fistula-in-ano is usually fistulectomy or fistulotomy, in which the fistulous tract is excised or opened across its entire length to identify the corresponding abnormal anal crypt. Following fistulectomy or fistulotomy, parents should be instructed to place the infant in a sitz bath after each bowel movement, at least twice daily, and separate the skin edges of the wound during bathing to promote healing by secondary intention. In addition, considerable debate exists with regard to making an effort to delineate a fistula at the time of abscess drainage. Some authors advocated that the probing of the abscess with fistulotomy under general anesthesia reduced the recurrence rates of perianal abscess and fistula-inano. ${ }^{9,10)}$ Another author reported that a diligent search for the fistulous tract by excessive probing of perianal abscess might lead to iatrogenic fistula formation. ${ }^{11)}$

Although surgical treatment is a widely accepted therapy for fistula-in-ano, it was recently suggested that fistula-in-ano in infants is a time-limited disorder and fistulotomy or fistulectomy should be avoided. ${ }^{6}$ However, Niyogi et al. ${ }^{3)}$ reported that conservative treatment of fistula-in-ano was associated with a longer hospital stay, longer antibiotics use, and more pain.

Although recurrent fistula after the treatment of perianal

\footnotetext{
Corresponding author: Jinyoung Park, MD, PhD. Department of Pediatric Surgery, School of Medicine, Kyungpook National University, Kyungpook National University Hospital, 130 Dongdeok-ro, Jung-gu, Daegu 41944, Korea 
abscess or fistula-in-ano is possible, there should be a high index of suspicion of the association with Crohn's disease in older children who experience recurrence. ${ }^{11}$

In conclusion, the management of perianal abscess and fistulain-ano remains controversial. Further randomized prospective studies are needed to determine new lesion classification and appropriate treatment of perianal abscess and fistula-in-ano.

\section{Conflicts of interest}

No potential conflict of interest relevant to this article was reported

See the article "Efficacy of conservative treatment of perianal abscesses in children and predictors for therapeutic failure" via https://doi.org/10.3345/cep.2019.00969.

\section{References}

1. Afşarlar CE, Karaman A, Tanır G, Karaman I, Yılmaz E, Erdoğan D, et al. Perianal abscess and fistula-in-ano in children: clinical characteristic, management and outcome. Pediatr Surg Int 2011;27:1063-8.
2. Chang HK, Ryu JG, Oh JT. Clinical characteristics and treatment of perianal abscess and fistula-in-ano in infants. J Pediatr Surg 2010;45: 1832-6.

3. Niyogi A, Agarwal T, Broadhurst J, Abel RM. Management of perianal abscess and fistula-in-ano in children. Eur J Pediatr Surg 2010;20:35-9.

4. Ezer SS, Oğuzkurt P, Ince E, Hiçsönmez A. Perianal abscess and fistula-inano in children: aetiology, management and outcome. J Paediatr Child Health 2010;46:92-5.

5. Gong Z, Han M, Wu Y, Huang X, Xu WJ, Lv Z. Treatment of first-time perianal abscess in childhood, balance recurrence and fistula formation rate with medical intervention. Eur J Pediatr Surg 2018;28:373-7.

6. Watanabe $Y$, Todani T, Yamamoto S. Conservative management of fistula in ano in infants. Pediatr Surg Int 1998;13:274-6.

7. Christison-Lagay ER, Hall JF, Wales PW, Bailey K, Terluk A, Goldstein $\mathrm{AM}$, et al. Nonoperative management of perianal abscess in infants is associated with decreased risk for fistula formation. Pediatrics 2007;120: e548-52.

8. Boenicke L, Doerner J, Wirth S, Zirngibl H, Langenbach MR. Efficacy of conservative treatment of perianal abscesses in children and predictors for therapeutic failure. Clin Exp Pediat 2020 May 15 [Epub]. https://doi. org/10.3345/cep.2019.00969.

9. Murthi GV, Okoye BO, Spicer RD, Cusick EL, Noblett HR. Perianal abscess in childhood. Pediatr Surg Int 2002;18:689-91.

10. Novotny NM, Mann MJ, Rescorla FJ. Fistula in ano in infants: who recurs? Pediatr Surg Int 2008;24:1197-9.

11. Macdonald A, Wilson-Storey D, Munro F. Treatment of perianal abscess and fistula-in-ano in children. Br J Surg 2003;90:220-1. 